\title{
La devaluación de lo político
}

\author{
Sergio Sevilla
}

\section{Titre / Title / Titolo}

La dévalorisation de la politique

The devaluation of the political

La svalutazione della politica

\section{Resumen / Résumé / Abstract / Riassunto}

El artículo revisa el análisis realizado por Habermas de la relación entre economía y política en Europa entre 1945 y 1989, y la quiebra de ese edificio que obliga a repensar un nuevo mapa categorial para lo político, con dos importantes efectos: la pérdida de confianza en una alternativa a la explotación y la desigualdad económica y también en la posibilidad de dirigir la economía desde instituciones políticas democráticas. Muestra que la aportación de Adorno a la formulación de ese espacio no se limita a dejar de lado la idea de una razón que proponga como meta ideales. El estatuto de su «crítica» no es, por tanto, ni kantiano ni hegeliano, aunque sea incesante el diálogo con ambos modelos desde una perspectiva micrológica para la acción política cuyo criterio de validez pasa a ser la lucha contra la «vida dañada».

L'article passe en revue l'analyse que fait Habermas de la relation entre l'économie et la politique en Europe entre 1945 et 1989, et de l'effondrement de cet édifice qui nous oblige à repenser une nouvelle carte catégorielle pour le politique, avec deux effets importants : la perte de confiance dans une alternative à l'exploitation et à l'inégalité économique et aussi dans la possibilité de diriger l'économie à partir d'institutions politiques démocratiques. Il montre que la contribution d'Adorno à la formulation de cet espace ne se limite pas à laisser de côté l'idée d'une raison qui propose des idéaux comme but. Le statut de sa «critique» n'est donc ni kantien ni hégélien, bien que le dialogue avec les deux modèles soit incessant dans une perspective micro-logique pour une action politique dont le critère de validité devient la lutte contre la «vie endommagée».

The article reviews Habermas' analysis of the relationship between economics and politics in Europe between 1945 and 1989, and the breakdown of such construction that forces us to conceive of a new categorical map for the political, with two important effects: the loss of confidence both in an alternative to exploitation and economic inequality and in the possibility of directing the economy from democratic political institutions. It shows that Adorno's contribution to the formulation of such space is not limited to the abandonment of the idea of a reason that proposes ideals as its goal. The status of his «critique» is therefore neither Kantian nor Hegelian, even though the dialogue with both models is incessant from a micro-logical perspective for political action whose criterion of validity becomes the struggle against "damaged life".

L'articolo passa in rassegna l'analisi di Habermas sulla relazione tra economia e politica in Europa tra il 1945 e il 1989, e la rottura di tale edificio che ci costringe a ripensare una nuova mappa categoriale del politico, con due effetti importanti: la perdita di fiducia tanto nella possibilità di un'alternativa allo sfruttamento e alla disuguaglianza economica quanto nella possibilità di dirigere l'economia da istituzioni politiche democratiche. Mostra che il contributo di Adorno alla formulazione di tale spazio non si limita a mettere da parte l'idea di una ragione che propone degli ideali come obiettivo. Lo statuto della sua «critica» non è, dunque, né kantiano né hegeliano, sebbene il dialogo con entrambi i modelli sia incessante in una prospettiva micro-logica per un'azione politica il cui criterio di validità diventa la lotta contro la «vita danneggiata».

\section{Palabras clave / Mots-clé / Key words I Parole chiave}

Acción comunicativa, democracia, Habermas, Adorno.

Action communicative, démocratie, Habermas, Adorno.

Communicative action, democracy, Habermas, Adorno.

Azione comunicativa, democrazia, Habermas, Adorno. 
El lugar pre-eminente que las sociedades complejas han asignado a «lo político», al menos desde la revolución francesa, se expresa de modo emblemático en la conversación, real o literaria, entre Napoleón y Goethe en que el segundo lamenta la imposibilidad de los modernos de acceder a la experiencia de destino de la tragedia griega, mientras Napoleón aduce que ese lugar lo ocupa la política en la experiencia del mundo contemporáneo. Ese verosímil intercambio verbal (si non é vero, e bene trovato) expresa el momento inicial del mundo que hemos conocido como «edad contemporánea», al que puso un punto final el debate filosófico sobre la postmodernidad, y la transformación del escenario europeo en 1989.

La política como destino de una época en que es dominante la convicción de que la humanidad no se plantea problemas que no esté capacitada para resolver, representa la confianza en la acción colectiva deliberada como modo de re-elaboración del mundo en que nos ha correspondido vivir.

La experiencia social de la pérdida de sentido, la invitación a abrirnos a la posibilidad del acontecimiento no inscrito en la lógica de la evolución social previa, la comprensión de que la civilización produce un malestar inseparable del género humano, la sospecha de vivir en una sociedad que produce el tipo de «hombre sin atributos» (Der Mann obne Eigensachaften), han sido algunas de las maneras en que el siglo veinte ha cobrado conciencia, teórica o artística, de que la lógica de la acción colectiva no conduce a ninguna forma, idealista o materialista, de reconciliación universal, a ninguna superación definitiva de la prehistoria de la humanidad.

Esta conciencia, con formas de expresión tan plurales, del carácter necesariamente abierto e incompleto del ser humano, de la imposibilidad de cerrarlo en un movimiento de totalización, que tan palpable ha sido en algunas de las experiencias mayores del siglo (Auschwitz, el Gulag o Hiroshima), establece el final del periodo de la política como heredera del destino que ha de ejercer la soberanía política como acción de un sujeto, y abre la necesidad de pensar de nuevo cuál es su espacio, su función y sus límites, históricamente mudables. Un desarrollo nuevo de la filosofía política, de sus nociones básicas y sus estrategias parece necesario. Si el pensamiento emancipatorio legado por el siglo diecinueve preveía la desaparición de la política como dominación, como fenómeno de poder, el resultado de sus intentos de realización parece exigir un nuevo pensamiento de lo político, al que han respondido algunos autores en las últimas décadas.

Ya nadie piensa en un proyecto, de matriz kantiana, en que una cierta idea de historia y de progreso permitan producir un arte de predicción política en que la cultura, como segunda naturaleza en el género humano, llegue a armonizarse con su primera naturaleza biológica. Pero tampoco parece posible aceptar la tesis de Isaiah Berlin según la cual: «No se puede combinar la libertad plena con la plena igualdad (...). También pueden chocar la justicia y la piedad, el conocimiento y la felicidad»; y concluir de ello, como punto final, que «ciertos valores humanos no pueden combinarse porque son incompatibles: de modo que hay que elegir» ${ }^{1}$. El pluralismo, así entendido, apunta como núcleo verdadero a la imposibilidad de totalización; pero con ello también abre el camino a una nueva reflexión sobre aquellas categorías de la política cuya articulación teórica no sería racional dejar en manos de cada cambio azaroso que tenga lugar en la correlación social de fuerzas. En tal caso, nada añadiría la reflexión a la violencia.

Un comienzo para la filosofía política que quiera estar abierto a comprender lo nuevo sin renunciar a intervenir activamente, aconseja una vuelta a la reflexión crítica sobre las tensiones existentes entre el sistema político y el sistema económico en las sociedades modernizadas complejas que vivimos. Revisaré, con este propósito, la posición sostenida al respecto por Habermas en Teoría de la acción comunicativa, que representa el momento más acabado de su diagnóstico y, con seguridad, el más necesitado de revisión.

El capítulo sexto de la hegeliana Fenomenología del Espíritu ya teorizaba los cambios en el mundo moderno, o mundo de la alienación, en términos de la interacción entre el poder y la riqueza o, si se quiere, entre el Estado y el mercado, con las formas de conciencia noble o vil que

R. Yahanbegloo, Conversaciones con Isaiah Berlin, Anaya \& Mario Muchnik, Madrid 1993, pág.189. 
la adhesión a cada uno de ellos genera en la modernidad. Como teoría de una sociedad que nos es más próxima, la que surgió después de 1945, a cuya crisis estamos asistiendo, Teoría de la acción comunicativa explicita con especial claridad la forma en que Estado y mercado han suplido las mutuas limitaciones, haciendo posible lo que Europa ha conocido, en ese periodo, como Estado de bienestar.

La intervención del Estado en la economía como «servicio público» se había introducido ya en 1888-1889 por el gobierno alemán de Bismark al legislar el seguro obligatorio de enfermedad, de vejez, de invalidez y de accidentes de trabajo. Quizá formaba parte de la llamada «vía prusiana» al capitalismo desarrollado; y, a pesar de los debates sobre la protección en la Francia de la tercera República, en 1889, desde una perspectiva más liberal el Estado no asume como propia la obligación y la transfiere al espacio de los trabajadores individuales a los que obliga a asegurarse. El cambio de perspectiva que en el resto de Europa no se generalizará, en un primer intento hasta 1918 y finalmente en 1945 en la forma que conocemos, comporta, al menos, dos modificaciones importantes de perspectiva: la conversión en obligación colectiva de lo que, desde una perspectiva liberal era un problema del afectado, y no del sistema; y la articulación de esa nueva obligación sistémica en términos de legalidad.

La innovación inicial es socialmente importante, pero su sentido político es problemático, puesto que se produce en un marco de democratización escasa, y en competencia con el surgimiento de una socialdemocracia en auge político. Su introducción tras el informe Beveridge en la Inglaterra de la segunda guerra mundial, y en el resto de Europa occidental tras la guerra, y su conversión en visión compartida, tanto por partidos socialdemócratas como democristianos, que hablan de una «doctrina social de la Iglesia»; todo ello unido a su apoyo en la teoría económica de Keynes, que de ningún modo cabe calificar de «socialista», acentúa la dificultad de algunos para valorar su puesta en cuestión actual como «crisis de la socialdemocracia». Ni los programas ni las propuestas se pueden conectar con los problemas derivados de la crisis de la teoría social y económica de Marx.
De hecho, la teorización de la socialdemocracia que presenta en su obra de los años ochenta Habermas parte de la afirmación de que «A la ortodoxia marxista le resulta difícil dar una explicación plausible del intervencionismo estatal, de la democracia de masas y del Estado benefacton ${ }^{2}$. Me parece pertinente tener en cuenta la crítica habermasiana a la teoría del capitalismo de Marx por dos razones; en primer lugar, es uno de los pocos textos, después del eclipse de la socialdemocracia de Bernstein y Kautsky, asociada a la segunda internacional, que elabora una reflexión filosófica acerca de la inutilidad de confiar en «contradicciones objetivas» internas al sistema económico. Su abandono, sin matices, de la dialéctica hace de él una buena expresión de la Europa del Estado benefactor que él mismo teoriza. En segundo lugar, ese cambio de posición conlleva la tesis implícita, pero cada vez aceptada de modo más general, de que no hay una alternativa sistémica a la economía de mercado; solo hay modos diversos de gestionarla.

Esa crítica se centra en distinguir, en la teoría marxiana del valor, y en la noción de alienación como plusvalía generada por el trabajo y apropiada por el capital, los elementos procedentes de la lógica sistémica y los elementos propios de la lógica de la acción social. Si deconstruimos los ingredientes de ese concepto en elementos que se mueven en dos niveles lógicos distintos, encontramos que ni es necesario ni es acertado aplicar la lógica dialéctica de las contradicciones a la comprensión del funcionamiento del sistema que, como tal, puede entenderse muy bien desde una perspectiva funcionalista, o luhmanniana. No hay, por decirlo así, una «base objetiva», o necesidad intrínseca de transformación inscrita en la lógica sistémica del capitalismo. No tiene, por tanto, sentido pensar que la acción de un sujeto social colectivo pueda intervenir superando esa contradicción y, aún menos, haciendo superflua la existencia del Estado. Los cambios proceden de acciones sociales exteriores a los sistemas, económico y político, que invaden los ámbitos de la acción intencional del entendimiento, como la personalidad, la cultura, la esfera

J. Habermas, Teoría de la acción comunicativa, II, Taurus, Madrid 1987, pág.485. En adelante abreviaré el título como T.A.C. 
de la formación de la opinión pública en que se basa la política, y produce fenómenos patológicos por colonización de una lógica por otra, la del mundo de la vida por la lógica sistémica.

Ello conlleva una tercera consecuencia problemática: hay que pensar una nueva filosofía política desde la perspectiva de un Estado que no solo no va a desaparecer, sino que ha de desempeñar una función muy relevante en la consecución de una forma de vida relativamente emancipada de imperativos sistémicos; la democracia ha de garantizar un Estado legítimo con fuerza suficiente para velar por la autonomía de la lógica propia del mundo de la vida. Veamos cómo surge esa demanda de orientación política, en la década de los ochenta, y con qué instrumentos cuenta la filosofía política de Habermas para intentar satisfacerla.

La institucionalización de la política, tal como la hemos conocido desde el final de la segunda guerra mundial, habría tenido como efecto un uso de la acción de gobierno como correctivo de los desequilibrios económicos, y una tensión estable y conscientemente gestionada entre capitalismo y democracia. Dicho en palabras de Habermas: «Aun cuando los problemas sistémicos tengan primariamente su origen en un tipo de crecimiento económico estructuralmente propenso a las crisis, los desequilibrios económicos pueden ser contrarestados por la intervención sustitutoria del Estado en las brechas funcionales del mercado» ${ }^{3}$. La intervención del Estado ha de ser, sin embargo, absolutamente respetuosa del principio de no poner en peligro las inversiones privadas; y ello no sólo por una razón ideológica, sino porque se entiende que el mercado tiene su propia esfera de validez indiscutida como mecanismo eficaz de producción y distribución de recursos socialmente necesarios. «Las intervenciones del Estado tienen, pues, que respetar la división del trabajo entre una economía dependiente del mercado y un Estado económicamente improductivo. Se puede distinguir tres dimensiones centrales de esta intervención: el aseguramiento militar y jurídico-institucional de las condiciones de existencia de la

T.A.C., II, pág.486 forma de producción, el influjo sobre la coyuntura económica, y una politica de infraestructura tendente a mantener las condiciones de realización del capital» ${ }^{4}$. A pesar de que la forma en que Habermas presenta la división Estado/ mercado sugiere que la intervención de aquél se atiene a su uso administrativo del poder, en realidad las tres dimensiones centrales que el Estado se compromete a respetar exceden ese ámbito y se convierten en una aceptación, apriorística y sin debate, de las condiciones de posibilidad y desarrollo de la economía de mercado como esencial; los demás elementos son instrumentales o, al menos, han de hacerse compatibles con él. Por ello, reconoce Habermas, la dualidad estructural «Estadomercado» tiene como consecuencia «que las tendencias a la crisis de raíz económica no solamente se vean modificadas, retardadas y absorbidas administrativamente, sino que, aún sin pretenderlo, se vean desplazadas al sistema de acción administrativa» ${ }^{5}$. Como se ve, la forma en que el Estado ha intervenido en la crisis económica de 2008 subsanando de los errores de la banca, está dentro de lo admitido como intervencionismo admisible.

Pero este intervencionismo solo resulta admisible si conlleva mecanismos de legitimidad política en los que se enmarque la acción administrativa. La teoría política estrictamente liberal y, especialmente el neo-liberalismo reaganiano, que entiende el sistema político con la lógica funcional del sistema económico, esto es, sin apelar a principios normativos, $y$ ateniéndose a compromisos fácticos a los que se accede según la correlación de fuerzas, es insuficiente para fundar y hacer funcionar el compromiso descrito. «El poder necesita de una institucionalización de más alcance que el dinero. El dinero queda anclado en el mundo de la vida a través de las instituciones del derecho privado burgués; de ahí que la teoría del valor-trabajo pueda partir de las relaciones de contrato entre los asalariados y los propietarios de capital. En el caso del poder, en cambio, no basta con el equivalente de derecho público que representa la organización de cargos; es menester, además, una legi-

\footnotetext{
T.A.C., pág.486

Loc.cit.
} 
timación del régimen de dominación política» ${ }^{6}$. Esa legitimidad que solo pueden prestar «los procedimientos democráticos de formación de la voluntad política» en una sociedad como la nuestra, paradójicamente pone precio, en términos funcionalistas, a la legitimidad democrática supuestamente superior.

Habermas omite esta consideración, que pondría en problemas el carácter último de los principios normativos de la razón práctica, para atenerse a lo que le parece una relación de tensión entre la organización del poder y la del dinero: «Entre capitalismo y democracia se entabla, en efecto, una indisoluble relación de tensión, pues con el capitalismo y la democracia compiten por la primacía dos principios opuestos de integración social» ${ }^{7}$. Casi treinta años más tarde, Zizek sacará conclusiones políticamente más radicales de esa oposición; e incluso llegará a explicar el éxito del modelo chino sobre la hipótesis de que ha sabido entender la conexión esencial (y no la tensión) existente entre autoritarismo político y capitalismo. Pero el contexto ideológico de 1982 era otro cuando Habermas problematiza la ecuación entre capitalismo y democracia, de un lado, y socialismo y Estado autoritario, de otro.

La tesis de Habermas introduce la perspectiva de lo que demanda el mundo de la vida; y, entonces, el dilema se formula así: «Desde la perspectiva de una teoría de la sociedad el sentido normativo de la democracia puede reducirse a la fórmula de que la satisfacción de las necesidades funcionales de la economía y de la administración, esto es, de los ámbitos de acción integrados sistemicamente, tiene que encontrar su límite en la integridad del mundo de la vida, es decir, en las exigencias de los ámbitos de acción que dependen de la integración social. Más, por otro lado, la dinámica capitalista propia al sistema económico solo puede preservarse en la medida en que el proceso de producción quede desacoplado de orientaciones hacia valores de uso» ${ }^{8}$.

La ruptura del pacto de complementariedad entre el sub-sistema económico y el político, en que se había

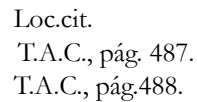

basado el Estado de bienestar promovido en Europa desde 1945, se produce ya en la década de 1990, y se agudiza a partir de 2008-2009, ante el riesgo de quiebra del sistema financiero; y cuando incluso políticos conservadores partidarios del Estado mínimo llegan a hablar de «re-fundar el capitalismo» (Sarkozy), se convierte en una prioridad para el Estado salvar las finanzas inyectando dinero, lo que exige recortar los capítulos de inversión pública característicos del Estado de bienestar: educación, sanidad y, en general, servicios públicos.

Los aspectos económicos de la crisis han de remitirse al análisis de los economistas, entre los que se dan las más enfrentadas contraposiciones a la hora de diagnosticar y prescribir recetas. Lo único falso en este terreno es el ideologema repetido por estos cuando aseguran que «no hay otro modo de salir de la crisis» que los recortes de servicios públicos que ellos prescriben.

Lo que ocupa a la reflexión es la dimensión política de la crisis, atendiendo a dos de sus aspectos: (a) Los efectos de la ruptura del «pacto» entre Estado y mercado, en el funcionamiento sistémico del primero; y las dificultades progresivas de legitimación para la democracia en el presente contexto. (b) La necesidad de volver a pensar la relación y las diferencias entre la política como sistema, y la política como acción auto-instituyente de la sociedad.

La evolución, en los últimos años, de los aspectos señalados por Habermas (1982) en forma de dilemas ha consistido, casi siempre, en una acentuación del poder de la lógica funcional en detrimento de la lógica de la acción y del sentido. Así, (a) el dilema que planteaba la necesidad de hacer compatible, en términos de Klaus Offe, la integración social con la integración sistémica, se ha desplazado en la dirección de una mayor «neutralización política de la esfera del trabajo, de la producción y de la distribución» en detrimento de «las regulaciones normativas de la acción y de las referencias de sentido de los sujetos» ${ }^{9}$ (se refiere a un artículo de Offe, recogido en un colectivo editado por F. Geraets, Rationality today, en 1979). Ejemplos de esa neutraliza-

Loc.cit. 
ción encontramos, abundantemente analizados, en el libro de Sennett La corrosión del carácter, que analiza los efectos negativos de esa «neutralización del trabajo» en la identidad personal. Esa decantación ha roto también el equilibrio que los partidos se esforzaban en mantener entre sostener «la confianza de los inversores privados y a la vez la confianza de las masas», según lo expresa Habermas. El precio, personal y político, impuesto a los cuidadanos ha sido muy elevado, y ha agravado, dicho en términos habermasianos, la colonización sistémica del mundo de la vida.

(b) El segundo efecto es la colisión entre dos modos de considerar la opinión pública, y la forma de operar en ella. En el sentido de una lógica de la deliberación «el consenso social es considerado como el primer eslabón en la cadena de formación de voluntad colectiva, y como base de la legitimación». Pero, desde la perspectiva del funcionamiento efectivo del sistema, «este mismo consenso se puede considerar también como resultado de una procura de legitimación, como eslabón terminal en la cadena de producción de lealtad de masas de que el sistema político se provee para librarse de las restricciones que le impone el mundo de la vida» ${ }^{10}$. En otras palabras, la opinión puede formarse de modo libre y argumentativo, y entonces es fuente de legitimación de las decisiones políticas; o bien puede producirse mediante prácticas de manipulación para generar una adhesión propagandística en que apoyar las decisiones consideradas convenientes desde un punto de vista funcional. La experiencia de la tensión entre esos dos modos de proceder la viven los ciudadanos, de modo claro, en la proximidad de los procesos electorales, que cada vez sienten como menos genuinos. Sin embargo, ejemplos de prevalencia drástica de las exigencias sistémicas sobre la legitimidad democrática y el sentido de la participación las hemos visto, ya en la pasada década, en la sustitución, consentida por los políticos profesionales, en Grecia o en Italia, al sustituir por vía parlamentaria un gobierno electo por otro «de técnicos». O al tener que repetir procesos electorales (Grecia, de nuevo), cuando no producen el resultado sistemicamente deseado, como si se tratara de un problema aritmético mal resuelto. Si a todo ello se añaden las prácticas oscuras introducidas en la era de la post-verdad, se acentúa el sentimiento social de pérdida de esa legitimidad democrática, en la que se apoyaba la aceptación política del sistema económico de mercado. Se degrada la participación, incluso reducida a lo meramente electoral; y desaparece la sensación de que la acción política dentro del sistema sea una acción con sentido. Un consenso general, a pesar de las dificultades ya señaladas en 1982 por Habermas, había hecho de los sistemas democráticos la institución política universalmente aceptable; Fukuyama llegó a ver en esa prevalencia el «fin de la historia», como la vio Hegel en el Estado de derecho.

Esa valoración de la democracia se ha degradado, a considerable velocidad y con graves consecuencias, en la gestión de la crisis económica. Abundan los indicios de acción política exterior a la lógica del sistema. (c) El tercer problema que Habermas señalaba era el que plantea «la segmentación del papel del elector, que es a lo que por lo general se reduce la participación política» ${ }^{11}$. De esa segmentación, Habermas señalaba como efecto negativo que la participación mediante el voto sólo influye (y esa influencia se reparte entre el ciudadano y el aparato de los partidos) en el reclutamiento de la clase política. Pero no influye, o no de un modo decisivo, en la «formación discursiva de la voluntad colectiva». En la medida en que esa formación de voluntad habría de reflejarse en los programas de gobierno, la experiencia se ha ido haciendo más negativa desde 1982. Los programas se acercan a las opciones de los electores sólo en la medida en que ésta es reflejada en las encuestas como teniendo incidencia comparativa en el voto; si no la tiene, o si hay un acuerdo entre los partidos más numerosos en excluir un tema del debate y de la confrontación, se puede dejar sin efecto la opinión del elector.

Si a ello se añade el hecho de que un programa electoral ganador no se convierte directamente en el programa del gobierno resultante de las elecciones, la 
«fragmentacion» de la participación del ciudadano se incrementa de modo considerable. La legitimidad creíble que pueden invocar a su favor las medidas del gobierno es progresivamente decreciente, y el propio concepto de participación cívica, como elemento definitorio de la democracia, se hace muy difuso, no solo en la práctica, sino también conceptualmente hablando.

Ya en los años ochenta, Habermas señalaba como elemento central del Estado de bienestar el hecho de que esa mermada legitimidad de la participación se viera compensada por la oferta de servicios sociales. Textualmente: «El sistema político no puede producir adhesión de la población a cualquier escala y a voluntad, sino que con sus programas sociales tiene que hacer también ofertas de legitimación sujetas a falsación» ${ }^{12}$. En ese contexto, el consenso entre los interlocutores sociales en torno a las condiciones del empleo se considera una pieza esencial de esa política. No puede extrañar que la quiebra actual de esas prácticas consensuales redunde negativamente en la capacidad del sistema para «producir adhesión de la población $\rangle^{13}$ (loc. cit.). (d) Otro efecto importante del pacto sobre complementariedad de los subsistemas era la neutralización de los conflictos. Habermas lo expresaba con cautela: «Con la protección de la esfera de la vida privada contra las consecuencias más llamativas de los imperativos sistémicos que operan en el mundo del trabajo, los conflictos en torno a la distribución han perdido su fuerza explosiva ${ }^{14}$.

Respetando los conceptos de Habermas, podemos decir que la democracia se está deslegitimando en la medida en que la lógica del sistema no ha encontrado barrera que la detuviese procedente del mundo de la vida. La desproporción de fuerzas entre ambas lógicas pone en cuestión la estrategia teórica seguida al equilibrar en el diagnóstico la sociología de sistemas de Parsons o Luhmann con la sociología de la acción de A. Schütz. Si no podemos aceptar la victoria final de la derecha hegeliana, hay que rechazar el funcionalismo sociológico para abrir paso a una concepción de la sociedad en que

\footnotetext{
TAC., II, pág. 491

Loc.cit.

TAC, II, pág. 494.
}

podamos apreciar el potencial transformador, y en todo caso no indefinidamente neutralizable, de los conflictos existentes. Ello no supone necesariamente la recuperación de una dialéctica afirmativa que supere los antagonismos mediante síntesis de los opuestos. Pero sí exige que la teoría social crítica de cabida a la comprensión de los conflictos y a la posibilidad de que la acción colectiva proponga soluciones para ellos bajo la forma de programas políticos. La comprensión funcionalista de las ciencias sociales resulta un obstáculo para cualquier forma de apropiación del proceso social. Y el espacio de resolución de problemas que la política hace posible se reduce, a la vez que se sustituye la deliberación por manipulación informativa.

Subrayaré dos aspectos de ese fin de época que son especialmente relevantes para el problema que tratamos.

A. Desde el punto de vista del concepto de democracia que aquí nos importa ahora, el diagnóstico de Habermas, a la altura de 1982, merece ser citado en extenso: «La implantación de derechos políticos fundamentales en el mismo marco de la democracia de masas significa, por un lado, la generalización del rol de ciudadano, pero, por otro, significa también la segmentación de ese rol respecto a los procesos efectivos de decisión; significa que la participación política queda vacía de contenidos participativos ${ }^{15}$. Lejos de desaparecer, esos ingredientes críticos han evolucionado, desde la década de los ochenta, hacia peor. La descarnada prioridad, concedida ya por las políticas de Reagan y Thatcher a los imperativos sistémicos de la economía, la falta de voluntad de pactar entre los agentes sociales, la tendencia a cuestionar todo lo público (desde el servicio del agua potable hasta las cárceles, sin excluir los ejércitos de invasión) fueron bien aceptadas, en los años 90, por la llamada «tercera vía»; y la crisis iniciada en 2008 se ha usado como argumento para profundizar y generalizar, sobre todo en Europa, aquella política. La segunda década de este siglo añade problemas de incremento de la desigualdad social, agravamiento de

TAC, II, pág. 495. 
los problemas de raíz ecológica y degradación del debate público que empeoran la situación.

B. La transformación sufrida en las décadas centrales del siglo veinte (digamos entre 1930 y 1970) tiene, en el análisis de Habermas, otro efecto central: «La conciencia cotidiana queda despojada de su fuerza sintetizadora, queda fragmentada» ${ }^{16}$. Y esa fragmentación de la conciencia de la ciudadanía pierde la capacidad de conceptualizar críticamente su propia cosificación en términos de lógica funcional. Una teoría de ese empobrecimiento cultural y de esa fragmentación de la conciencia cotidiana está pendiente de elaboración; pero, sin duda, esa ausencia es funcional para el buen funcionamiento de una participación cívica y social menguantes. Tampoco contribuyen a la calidad de la acción política el tipo de uso predominante de las nuevas tecnologías de la comunicación que fomentan un activismo sin comprometerse con programas.

Los cambios acontecidos a partir de la devaluación normativa de la democracia y de la conciencia política tratada con una lógica funcional, pueden explicar la enorme transformación operada en el subsistema de la política, y la necesidad de extender la reflexión al terreno de «lo político».

\section{II}

Para abordar la pregunta por el espacio de lo político, me parece conveniente pensar los cambios habidos desde 1989 en la «agenda» de la política, esto es señalar los problemas nuevos que se le suscitan a la acción política como efecto, parcialmente al menos, de la destitución de «lo político» de su anterior función de configurar el destino de los seres humanos.

En las últimas décadas se ha vuelto casi un lugar común la distinción entre esas dos categorías, «la política»/»lo político» en discursos filosóficos tan dis-

TAC, II, pág.501. tantes entre sí como el de Ernesto Laclau y el de Jean Luc Nancy, por poner nombres propios.

Para trazar esa distinción puede bastar con que pensemos en algunos ejemplos clásicos que hacen ver su pertinencia. Cuando Aristóteles nos propone entender el vínculo entre ciudadanos desde el modelo de la amistad, o valora formas de gobierno desde esa perspectiva, construye categorías muy básicas para pensar las políticas efectivas desde el plano de «lo político». Lo mismo sucede en la Crítica de la razón pura al formular Kant el interés de la razón por la libertad y por el uso configurador que hacemos de ella. Ambas perspectivas trenzan la explicación de los hechos con la elaboración de un punto de vista normativo que hace posible la crítica. Distinguir entre lo fáctico y lo normativo no significa tener que separarlos.

La política como actividad emancipatoria queda situada, desde Kant, en la posibilidad de un futuro mejor, que Bloch pensó como «Principio esperanza», o Habermas como «Interés emancipatorio de la razón». El sentido de la acción política deriva entonces de la contribución que haga a la construcción en el futuro de una sociedad de hombres no cosificados. El cuestionamiento de esa dimensión caracteriza al pensamiento de lo político en el presente, que reduce la acción a mera gestión.

Al carácter híbrido de facticidad y normatividad de esos dos modelos se opone la propuesta de Carl Schmitt de reducir el espacio de lo político a la correlación de fuerzas alcanzada en cada caso por la confrontación entre «amigos»y «enemigos». Es la pertenencia fáctica a un grupo lo que, una vez asumido, decide. En cualquiera de los modelos entendemos que lo que se diseña no es lo que llamamos una política, sino más bien, trazan los límites de un espacio teórico organizado por categorías que crean un sentido para la ulterior reflexión política. A ese plano de inmanencia me refiero al hablar de «lo político», y en referencia a él me ocuparé de algunos desarrollos llevados a cabo por Adorno.

Lo que importa en este punto es señalar la convergencia entre la herencia de la comprensión de la política como emancipación y el desplazamiento de la política que cede su lugar de privilegio a la economía que dirige 
el proceso de globalización. Esa tendencia se opone a la propia del Estado de bienestar que, como reconoce Teoría de la acción comunicativa, basa la estabilidad política en una transacción en que por un lado reconoce la libertad de acción y organización a los partidos obreros, y a cambio acepta la economía de mercado compensada con cierto grado de dirección política.

En un contexto histórico-político como ese adquiere pleno sentido que el hundimiento de la economía dirigida desde la política por el Estado del socialismo real de lugar a planteamientos filosóficos como el de Albrecht Wellmer cuando se pregunta si el hundimiento de las sociedades del «socialismo real» constituye una forma de falsación, popperiana o no, de la teoría de Marx, que se pensaba a sí misma desde la unidad de teoría y praxis y el control social de la satisfacción de las necesidades.

La pregunta de Wellmer, el más adorniano de los habermasianos, no era impertinente pero, a mi modo de ver, no se planteaba con claridad hasta qué punto la tesis undécima sobre Feuerbach no se inscribe en el marco de la filosofía política, sino en el espacio de la filosofía de lo político.

Los análisis teóricos acerca de lo que podemos hacer después de la desaparición de lo que algunos entendieron como muerte (por realización efectiva) de la filosofía, y la fuerza que han cobrado posturas como la de Carl Schmitt, vuelven a contraponer la idea de lo político como una mera cuestión de fuerzas en presencia con la experiencia de que es imposible gobernar sociedades modernas complejas sin una dosis alta de racionalidad teórica, en su gestión y en su incesante innovación.

La aportación de la teoría crítica no es entonces una cuestión directamente política, sino una pregunta filosófica por el trazado que realiza del plano de lo político.

\section{III}

Pero también funciona en sentido inverso ese desplazamiento entre la agenda de la política y el análisis de lo político. Establecer la problemática de esa agenda puede ser la condición necesaria para acceder a un diagnós- tico actual de lo político puesto que su desplazamiento, como es de esperar, sigue de cerca a las modificaciones de agenda que el mundo histórico de los agentes políticos ha experimentado.

Podemos partir convencionalmente de la fecha de 1989 en que el derrumbe de la experiencia soviética tiene como efecto que las críticas al sistema capitalista pierdan toda conexión con una propuesta de recambio sistémico. Con ello se pierde la confianza en una posibilidad alternativa de suprimir la explotación económica socializando la plusvalía, pero también en la posibilidad de dirigir la economía desde instituciones políticas.

Intentaré formular, con brevedad, los problemas políticos que aparecen, o adquieren una nueva formulación, tomando prestada la tesis de E. Traverso según el cual, en la Europa actual «ocurre, simplemente, que hemos entrado en un nuevo régimen de historicidad $\rangle^{17}$. Con esa denominación designa una ruptura que no es una ocurrencia singular de Traverso, y que se llena de contenido con solo hacer un mínimo esfuerzo para evocar los hechos. Por poner un ejemplo en ese sentido, citaré un breve texto en el que Alfonso Sastre caracteriza la política del siglo veinte, claramente desde una perspectiva emancipatoria, como un cúmulo de «tensiones, contradicciones y desgarros, cuando se trata de explicarse y de vivir la alianza entre Hitler y la U.R.S.S., o de la confrontación entre comunistas y socialdemócratas, o del viejo y renovado debate entre libertarios

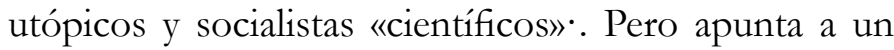
nuevo régimen de historicidad cuando extrae la siguiente conclusión de esas tensiones, ya en los años noventa del siglo veinte: «Hoy ha quedado probada una terrible y elocuente verdad: que todo socialismo es utópico» ${ }^{18}$ Esa nueva historicidad afecta incluso a los programas de las fuerzas políticas que aparentemente permanecen. El nacionalismo, por ejemplo, desplazó el énfasis, propio de los años treinta del siglo veinte, en la raza o en «la tierra» para basarse en una defensa de la idea de «identidad nacional». Otro ejemplo lo da la socialdemocracia, que

E. Traverso, Las nuevas caras de la derecha, Siglo veintiuno editores, Buenos Aires 2018, pág. 51.

18 «Pequeñas notas para el pórtico de un gran libro», en Peter Weiss, La estética de la resistencia, Argitaletxe HIRU, S.L., Estella-Navarra, pág. 13. 
ya pasó del marxismo reformista de Kautsky al Estado de bienestar keynesiano, y ahora convive sin dificultad con el liberalismo económico. Otro ejemplo de continuidad con cambio lo ofrecen las izquierdas surgidas en la crisis económica de la primera década del siglo, como Syriza o Podemos, que tienen programas moderados si los comparamos con el que en 1970 presentó la Unión de la Izquierda en Francia o el Partido comunista italiano en esa misma década. Como transformación que afecta de modo trasversal a la derecha y a la izquierda señala Traverso que mientras «el siglo xx tenía sus grandes partidos de masas dotados de una base ideológica, una base social, una estructuración nacional y un arraigo en la sociedad civil $(. .$.$) todo eso no existe más { }^{19}$. Los efectos son impactantes y de largo alcance: los intelectuales han sido reemplazados por los estrategas en comunicación, la ideología se borra como factor decisivo, y el nacionalismo se convierte en resistencia contra las amenazas de la globalización. Esa incomparecencia de ideas y valores tiende a convertir la acción política en mera gestión institucional; y va acompañada por una preocupación general por la seguridad, único rasgo socialmente compartido, que puede usarse para recortar libertades justificadas por el objetivo de luchar contra el terrorismo.

Una tal transformación en lo que podemos llamar «la política realmente existente» provoca un desplazamiento de lo político en su moderno protagonismo como «destino», es decir, como lugar en que una sociedad afronta colectivamente sus problemas de modo autónomo, y cualquier cambio en la reflexión política depende en su sentido de las funciones recortadas al ámbito de lo político. Para contribuir a esa reflexión propongo un diálogo con ciertos textos de Adorno pero, sobre todo, con su concepción de lo político.

Lo que aporta Adorno a la formulación de ese espacio no se limita a dejar de lado la idea de una razón que proponga como meta ideales que funcionen como una «finalidad sin fin», sin que ello implique considerar la sociedad fenoménicamente dada desde un punto de vista resignado. El estatuto de su «crítica» no es, por

Traverso, opág.cit., pág. 47 tanto, ni kantiano ni hegeliano, aunque sea incesante el diálogo con ambos. El criterio de validez de la acción política pasa a ser la lucha contra la «vida dañada», ese difícil concepto con el que esbozan constelaciones los aforismos de Mínima Moralia hasta lograr un perfil inusual de las sociedades modernizadas.

Según esa perspectiva, a la «nueva antropología» degradada de Carl Schmitt se opone vanamente, por parte de ciertas políticas marxistas, una concepción inadecuada de la praxis que re-conduce a aquella. El primer problema que ha de volver a pensarse es el que plantea la concepción en uso de la noción de praxis, es decir el modelo de acción que impone una sociedad que ha institucionalizado la gestión de las necesidades, y el espacio de las libertades, reforzando la cosificación de los agentes, económicos y políticos, reduciendo la acción a gestión, que se atiene a lo dado como intocable («es lo que hay», decimos) y desconoce la capacidad que toda acción tiene de iniciar procesos nuevos. Por decirlo con sus palabras, «Al que, como se dice, se atiene a la praxis, al que tiene intereses que perseguir y planes que realizar, las personas con las que entra en contacto automáticamente se le convierten en amigos o enemigos (...). De este modo se produce un empobrecimiento en las relaciones entre personas» ${ }^{20}$. Una tal concepción de la praxis conecta según Adorno a «los caudillos del terror» con «la mirada evaluadora del manager que señala al aspirante su puesto» ${ }^{21}$. Se trata de una reducción de la praxis a un nivel a la vez utilitarista y regresivo, en el que convergen dos modos de la acción social, el de las sociedades capitalistas y el de las totalitarias. El vínculo social, en ambos casos, se ha recortado a la medida de la productividad económica y la dominación política. Construir una alternativa eficaz no es una tarea meramente política puesto que requiere una nueva concepción de lo político y una revisión de la articulación entre lo teórico y la acción.

Adorno propone entender la praxis, no como la formulación de un «ideal» o de una utopía, sino desde la idea de que lo que la acción ha de traer al presen-

\footnotetext{
Adorno, O.C.4, Akal, Madrid 2004, pág. 136.

21 Op. Cit. p. 137.
} 
te descansa en la apertura de una posibilidad esbozada en Mínima Moralia: «Quizá la verdadera sociedad llegue a hartarse del desarrollo y deje, por pura libertad, sin aprovechar algunas posibilidades en lugar de pretender alcanzar, con desvariado ímpetu, ignotas estrellas» ${ }^{22}$. La política emancipatoria contemporánea no tiene que guiarse por un ideal que pueda mutar en ideología, o en directa manipulación. Dejados atrás los fenómenos no discutibles del mal, a saber el hambre y el sufrimiento, característicos del reino de la necesidad, se trata de acceder a «una socialización no-coactiva» y a «una relación con la naturaleza reconciliada y pacífica». Lo que hay que traer no son los rasgos de una utopía afirmativa, sino los criterios para guiar racionalmente prácticas transformadoras del empobrecimiento y la cosificación. Lo cual exige también un nuevo modo de hacer ciencias sociales que no reduzca su objeto a la medida del funcionalismo o de la teoría de sistemas, es decir, que mantenga la capacidad de crítica y de propuesta.

Aceptada la pérdida de la perspectiva de totalidad, la teoría crítica afronta la posibilidad de trascender el «reino de la necesidad», que limita la acción política a la gestión, para explorar lo político desde la perspectiva de nociones como «socialización no-coactiva» y «relación no violenta con la naturaleza», no menos problemáticas que el estatuto del «mundo inteligible» kantiano.

El tratamiento que hace Adorno de la noción de praxis hace inviable, para entender lo político, el recurso a la división entre lo teórico y lo práctico tal como la pensaron Kant y Marx, o como resurge, en el paradigma lingüístico-crítico, en la teoría de los actos de habla.

En un escrito temprano como Actualidad de la filosofía articulaba ambas nociones en torno a la práctica de la interpretación dialéctica que es propia de la teoría crítica. «Cuando Marx reprochaba a los filósofos que solo habían interpretado al mundo de diferentes formas, y que se trataba de transformarlo, no legitimaba esa frase tan solo la praxis política, sino también la teoría filosófica» ${ }^{23}$. Esta es la raíz de la actualidad filosófica del concepto de «lo político»

22 Adorno, O.C. 4, pág.163.

23 Th.W.Adorno, Actualidad de la filosofía, Paidós, Barcelona 1991, pág. 94.
La propuesta de Adorno se centra en dos motivos que afectan a las concepciones de la racionalidad. El primero es el carácter internamente contradictorio de la «praxis» en las sociedades complejas, que han hecho del productivismo un ideal ${ }^{24}$. El segundo es la negativa a considerar la teoría como reflejo de un mundo de objetos; la verdad no es ya correspondencia entre cosas e ideas, sino elaboración activa de experiencias por un lenguaje que puede ser el de la teoría o el del arte. Si el conocimiento es espontaneidad es por ello un tipo de acción no separable del mundo que configura.

La primera línea de reflexión se extiende desde el texto ya citado de 1930 hasta la siguiente afirmación de Dialéctica negativa: «Una praxis indefinidamente aplazada ya no es la instancia de apelación contra una especulación autosatisfecha, sino la mayoría de las veces el pretexto con el que los ejecutivos estrangulan por vano al pensamiento crítico del que una praxis transformadora habría menester ${ }^{25}$. Esas dos formas de funcionar opuestas que coexisten, no sin problema, en la noción de praxis delatan hasta qué punto la acción, en las sociedades burguesas, ha dejado de representar la actividad de la libertad. Y se exalta el productivismo como ideal colectivo ocultando tras esa connotación de libertad la realidad de la explotación y el control generalizados. También en Mínima moralia abundan análisis de la sociedad moderna en ese mismo sentido.

La segunda reflexión trata del sentido de la teoría y es menos explícitamente visible, pero acompaña desde el comienzo: la interpretación filosófica es la respuesta no a un problema, sino a un enigma y «la contestación no se queda en el ámbito cerrado del conocimiento sino que es la praxis quien la da. La interpretación de una realidad con la que se tropieza y su superación se remiten la una a la otra» ${ }^{26}$. Esa remisión recíproca no está analíticamente perfilada, pero está conectada con otra de las tesis sobre

\footnotetext{
${ }^{24}$ Judith Butler evita este problema mediante la noción de «política de la performatividad», que presenta como una ampliación moral de la política que, de este modo, no se limita a los valores jurídicos del Estado de derecho e incide en una valorización primordial de la vida humana tratada como sujeto de derechos que han de ser reivindicados mediante la lucha política. (J. Butler, Cuerpos aliados y lucha política, Paidos, Barcelona 2017, pág. 209).

25 Th.W.Adorno, O.C.,6. Akal, Madrid 2005, pág. 15.

${ }^{26}$ Actualidad, pág.94.
} 
Feuerbach en la que Marx recuerda el mérito del idealismo como descubridor del carácter activo del sujeto del conocimiento. La interpretación dialéctica es elemento inseparable de la acción sobre el mundo, que no puede quedar ideológicamente reservada a la intervención de un colectivo político que actúa limitándose a aplicar una directriz. Si lo hace, restando valor al momento teórico, puede degenerar en cualquier forma de activismo degradado. El recurso a la praxis como criterio nos exige volver a pensar la triada Theorein, Praxis, Poiesis y, más en concreto, su conexión definitoria del espacio de lo político, desde una noción no recortada de «acción».

De un modo similar al carácter activo de la teoría, convertida en ars inveniendi de modelos, la exigencia de que el lenguaje del arte aporte el elemento particular de la experiencia que escapa al concepto conecta también a la interpretación filosófica con el arte, y la perspectiva de la Poiesis entra a formar parte de la búsqueda de la verdad. La «exactitud (del discurso resultante) se controla por la desaparición de la pregunta $»^{27}$ que, como enigma, suscitó la indagación. Lo que está en juego para una teoría de la acción no es ya un espacio de validación de la teoría desde fuera, o un ámbito de realización de las disposiciones esenciales del ser humano. Lo que cuenta es la posibilidad de hacer desparecer el sufrimiento que acompaña a la experiencia falsa que se incorpora a la vida dañada. Lo que permite elucidar los elementos con que abordamos el campo de lo político desde la teoría crítica no se limita a propiciar ya ninguna sociología positiva, como tampoco busca ninguna ontología del ser social. Hemos de buscar un modelo interpretativo de la acción impura, esto es, en tanto que forma parte del Theorein y de la Poiesis. El espacio de la emancipación afirmativa queda sustituido por una libertad negativa que se sigue de la «desaparición de la pregunta».

Eso afecta al modo de preguntar, una vez alterada la comprensión que suponemos de lo teórico, por lo práctico y lo producido por las artes y las técnicas, pero también han cambiado las propias preguntas que han de dirigir la indagación en el ámbito de lo político.

Adorno, Actualidad..., pág.99.
La conexión entre los problemas de la política y la teorización de lo político ha de tomar en consideración tres puntos de contacto:

a. La constatación de que los temas que constituyen la agenda política cambian históricamente, y que esta no se ocupa de cuestiones atemporales que afecten lo mismo a la «bella vida ética» que al mundo de la alienación, por usar caracterizaciones hegelianas. Pero tampoco hay logros definitivos ni formas estables en una actualidad como la nuestra: el valor de la «democracia representativa» pasó de ser el de una cáscara «meramente formal» en los años treinta del siglo veinte, a convertirse en la finalidad del proceso de civilización, en los años noventa, y llegar a ser hoy el objetivo a batir para quienes programan la supremacía definitiva del sistema económico sobre el político. La pérdida de pre-eminencia de lo político es indicio de cambios no intencionales, pero también de luchas políticas por el dominio del devenir de la sociedad.

b. Contrariamente a la tendencia derivada de la teoría de los actos de habla en la segunda generación de la Teoría Crítica, no podemos reducir a una cuestión ética el cúmulo de perspectivas y valores implicados en un diagnóstico crítico de nuestra época. Es un referente en este sentido el trabajo de Marx, que parte de una crítica de los ideologemas incrustados en las ciencias sociales que nos permiten entender nuestra sociedad y, por tanto, pueden también falsear nuestra intelección. La teoría crítica, por tanto, no tiene como modelo prioritario un código moral sino un análisis de la sociedad existente, guiado por la voluntad de conocerla, y cuyo peligro mayor, el que pide explicitar una instancia crítica, es la ideología como «falsa conciencia», al servicio de intereses particularistas que ella misma intenta encubrir. Se hace sentir desde esta perspectiva la falta de una crítica actual de la economía política, en lugar de la moralización o la simple ausencia de diálogo científico sobre los cambios producidos en las últimas décadas; como se hace sentir también el reduccionismo de lo social que operan las sociologías funcionalistas. Como las 
indicaciones de Minima moralia sugieren, la crítica del funcionalismo exige ir más allá de la crítica de la razón instrumental, y en otras direcciones.

c. La conversión en problema que ha de ser tratado políticamente de determinadas situaciones previamente pre-políticas como la apropiación minoritaria de la riqueza que produce miseria material masiva, o la manipulación ideológica sistematizada que provoca el embrutecimiento de la vida social y personal. La combinación de ambas permite la «lógica del mundo administrado» mediante el creciente poder de la técnica ${ }^{28}$. La posibilidad que esta nos da, tanto de controlar el nacimiento como de administrar la muerte (Auschwitz, Hiroshima), merma seriamente el uso autónomo ${ }^{29}$, por tanto político, de las fuerzas humanas. La vida hipersocializada queda sometida a los imperativos funcionales, en detrimento tanto de la espontaneidad como de la moralidad elegida, lo cual nos coloca ante hechos estructurales resistentes a la acción política, que, sin embargo, se ve condicionada por ellos.

De esta crítica a la sociedad del presente es indeseable poner entre paréntesis la particularidad del momento histórico, caracterizado por un cierto nivel de desarrollo tecnológico y una gestión instrumental del poder político y económico. Al incorporarla, Adorno está dando algún ejemplo de la proyección de lo político sobre la política. Su diagnóstico ha de aceptar la imposibilidad de proponer normas positivas universalizables, y ha de conformarse con rechazar, vía negativa, lo indeseable.

El diagnóstico que propone Adorno es incomprensible sin una revisión sincronizada de la teoría de la racionalidad y de la agenda de la política. Pero no puede suponer una conexión directa entre ambos niveles. No

\footnotetext{
28 Butler defiende aquí la pertinencia de transformar en cuestiones políticas dos aspectos pre-políticos de la vida social, el «sufrimiento inútil» y el «trabajo no reconocido» revisando la oposición entre vida corporal y vida espiritual a través de la introducción de una «política del cuerpo» (op. cit., pág.206).

${ }^{29}$ Es interesante notar la crisis que determinadas filosofías del siglo veinte han señalado en la noción de autonomía que desde Kant había funcionado como emblema de la moral y la política de la ilustración. En sentidos contrarios, conviene tener en cuenta a Heidegger y a Castoriadis. Puede ser muy útil tener en cuenta las nociones de «precariedad», «vulnerabilidad» que Butler usa para matizar en aspectos relevantes el idealismo de la autonomía, drásticamente opuesta a la heteronomía, desde una perspectiva de ilustración. Véase págs. 210-212 de la obra citada.
}

se trata de añadir «contenidos» a una moral «formalista», ni de «completar» con finalidades a una racionalidad instrumental. El problema filosófico de desplazar la inalterable fijeza de los límites del mapa de la razón no puede resolverse aceptando, en términos estrictamente kantianos, la construcción «positiva» de una noción de libertad que no se puede afirmar como existente. Si bien el modo de entender la tercera antinomia es determinante de las distintas posiciones que marcan el desarrollo del idealismo alemán, Adorno traza su propio posicionamiento eligiendo, como punto de partida un texto de Kant en que la libertad no equivale a causalidad por la razón, sino a la capacidad de iniciar cambios en el mundo: «Aun cuando se conceda una facultad trascendental de la libertad capaz de iniciar los cambios del mundo, tal facultad debería, en cualquier caso, hallarse solo fuera de él (a pesar de lo cual, sigue siendo una pretensión audaz la de admitir, fuera del conjunto de todas las intuiciones posibles, un objeto que no puede darse en ninguna percepción posible)» ${ }^{30}$.

En contraposición a esa lectura hegeliana que ve en la crítica, kantianamente efectuada, una confesión de la impotencia de la razón para realizar sus fines, propongo conservar la raíz última de una teoría de la acción potente, pero descreída de la mera obediencia a ideas, o a imperativos, previamente establecidos, o simple «apropiación» de nuestra esencia alienada. La crítica ha de considerar con todas sus consecuencias la capacidad que tiene la acción racional para producir lo imprevisto, o para dar un sentido nuevo al acontecimiento.

Un concepto que puede operar el cierre del espacio de lo político, y a la vez la apertura por fin aceptada de la política, es una especial acepción de la libertad ofrecida por Kant en la primera Crítica y que se aleja de la idea de realizar lo previamente determinado como posible tanto como de la obediencia a imperativos, por

\footnotetext{
Kant, Crítica de la rąón pura, A 451/ B 479. El texto original dice: «Wenn auch indessen allenfalls ein transzendentales Vermögen der Freiheit nachgegeben wird, um die Weltveränderungen anzufangen, so würde dieses Vermögen doch wenigstens nur ausserhalb der Welt sein müssen (wiewohl es immer eine kühne Anmassung bleibt, ausserhalb dem Inbegriffe aller möglichen Anschauungen, noch einen Gegenstand anzunehmen, der in keiner möglichen Wahrnehmung gegeben werden kann)». Suhrkamp, Frankfurt 1980, S. 433.
} 
categóricamente que se presenten. Como observación a la idea de una constitución civil perfecta, Kant introduce el siguiente comentario: « ...nadie puede ni debe determinar cuál es el supremo grado en el cual tiene que detenerse la humanidad, ni, por tanto, cuál es la distancia que necesariamente separa la idea de su realización. Nadie debe ni puede hacerlo porque se trata precisamente de la libertad, la cual es capaz de franquear toda frontera determinada» ${ }^{31}$. Esa noción de libertad, que no está contenida dentro del mapa de la razón, pone en cuestión el designio de trazar los límites de un mapa definitivo, y por ello se incorpora sin violencia a versiones no trascendentales de la crítica que no postulan la idea de un estadio histórico al que la humanidad deba llegar, y limitan su ejercicio al propio de una dialéctica negativa. Son ejemplo de ella la marxiana crítica de la ideología o la genealogía nietzscheana que Adorno incorporó como formas legítimas de uso del punto de vista de lo inteligible. Con ello nos muestra el modo del pensar que

\footnotetext{
31 I.Kant, Crítica de la razón pura, Alfaguara, Madrid 1978, pág. 312. Traducción de Pedro Ribas.
}

hace posible una noción de lo político que permita el ejercicio de la teoría en cuanto crítica.

\section{Referencias bibliográficas}

Adorno, Theodor W. Actualidad de la filosofía. Barcelona: Paidós, 1991.

Butler, Judith. Cuerpos aliados y lucha política. Barcelona: Paidós, 2017.

Habermas, Jürgen. Teoría de la acción comunicativa, II. Madrid: Taurus, 1987.

Kant, Immanuel. Crítica de la razón pura. Madrid: Alfaguara, 1978.

Traverso, Enzo. Las nuevas caras de la derecha. Buenos Aires: Siglo Veintiuno Editores, 2018.

Weiss, Peter. La estética de la resistencia, Estella-Navarra: Argitaletxe HIRU, S.L., 2013.

Yahanbegloo, Ramin. Conversaciones con Isaiab Berlin. Madrid: Anaya \& Mario Muchnik, 1993. 